\title{
Electromyographic assessment of muscle fatigue after the Biering-Sorensen test in subjects with low back pain who underwent the McKenzie treatment
}

\author{
MAGDALENA JABŁOŃSKA*, JACEK MĄCZYŃSKI, \\ ANNA FRYZOWICZ, MAŁGORZATA B. OGURKOWSKA \\ Poznan University of Physical Education, Poznań, Poland.
}

\begin{abstract}
Purpose: Chronic low back pain is a common disorder affecting about $80 \%$ of the population, caused by a disorder in the muscular system. The main aim of this study was to assess muscle fatigue during the Biering-Sorensen Test in people with chronic low back pain who underwent the McKenzie treatment. Methods: Tests were conducted on 19 men (mean age of 41.4 years) with chronic non-specific lumbar-sacral pain syndrome, working in the seated position in front of a computer. Assessment of changes in fatigue of erector spinae, gluteus maximus and biceps femoris using surface electromyography during the Biering-Sorensen Test and subjective pain assessment using Visual Analog Scale were conducted on three test dates. Time-frequency representation of the electromyographic signal (Fourier transform) was used for the examination of muscle fatigue. The McKenzie method of diagnosis and therapy was applied before and between the tests. Results: The McKenzie therapy resulted in increased endurance (test duration) of the examined spinal muscles between the 1 st and 3rd test date $(p=0.043)$, and a systematic decrease in pain assessment on the three test dates $(p=0.000-0.004)$. Correlations were obtained between slope coefficients of the simple regression of median frequency of electromyographic signals on the one hand and duration of the BST ( $p=0.000-0.012)$ and anthropometric parameters (body mass, height and body mass index, $p=0.001-0.020$ ) on the other. Conclusions: The McKenzie method is an effective tool in reducing the level of lumbar pain and improving muscle endurance.
\end{abstract}

Key words: EMG, muscle fatigue, McKenzie method, low back pain, Biering-Sorensen test

\section{Introduction}

Chronic low back pain (LBP) is an extremely common disorder, affecting about $80 \%$ of the population and appearing at different stages of adult life [3], [21]. Characteristic features of back pain are its recurrence (in $60 \%$ of the population) but also spontaneous recovery or reduction of pain $(75-90 \%$ of the population) [16]. Available studies indicate that the main cause of abnormalities and pain in the lumbar and sacral spine are changes in the muscular system, such as disturbances of muscle balance or muscle activation, which lead to spinal stability disorders [14], [41]. Mahato [23] identifies potential LBP risk factors. These include, but are not limited to, musculoskeletal changes, alterations in muscle functional capacity (e.g., strength and endurance), changes in muscle activation patterns [18] or psychological changes associated with LBP. Dysfunctions of spine stabilising muscles, decreased muscle capacity or increased anterior pelvic tilt and increased lumbar lordosis are the consequence of passive flexion postures (slump sitting). Such a posture may lead to a decrease in the activity of active spinal stabilisers, i.e., the muscular system, and an increase in the load on the passive stabilisers [33].Moreover, it is even claimed that reduced muscle endurance is a predictor of LBP development [26], [42].

One of the most advanced muscle endurance testing techniques is based on the analysis of median fre-

\footnotetext{
* Corresponding author: Magdalena Jabłońska, Department of Biomechanics, Poznan University of Physical Education, ul. Królowej Jadwigi 27/39,61-871 Poznań, Poland. E-mail: magdalena.zygmanska@wp.pl

Received: March 14th, 2021

Accepted for publication: June 22nd, 2021
} 
quencies (MF) of electromyographic signals. When erector spinae muscles (ES) get tired, time shifts in MF towards lower frequencies can be observed [11], [37]. During electromyographic assessment of muscle fatigue, asymmetric patterns of muscle contraction activity are also observed. Such an imbalance of longissimus component of the lumbar ES was detected in LBP subjects while lifting [25]. It contributes to asymmetric back movements and, consequently, to spinal load imbalance and pain during everyday activities [35].

The Biering-Sorensen Test (BST) can be used to assess the endurance of back muscles. It consists of determining the maximum time of maintaining a position in which back muscles work isometrically. The authors of the test analysed the results of 900 people and came to the conclusion that shorter time of maintaining such position was a predictor of LBP in the next year in men [7]. The BST is used particularly before and after rehabilitation [13]. A number of studies on the phenomenon of LBP confirmed the appropriateness of the BST used to evaluate the endurance of trunk muscles. It provides a reliable measure of how long a particular position can be maintained and thus can help distinguish between subjects with and without non-specific LBP. Individuals without lumbar pain were able to maintain a position much longer than people with LBP [9], [22]. In the BST, the involvement of hip extensor muscles (e.g., BF - biceps femoris, GM - gluteus maximus) is also noted. Their fatigue indicates that load is distributed between the back muscles and hip extensor muscles during the test [19].

Many researchers emphasise the close relationship between subjective and objective assessment of muscle fatigue, [6], [12], [27]. According to the above-mentioned authors, not being able to maintain a position for long was associated with certain mental disorders or negative beliefs concerning the efficiency of the participants' backs. Due to the fact that LBP strongly correlates with the condition of the trunk muscle corset, there is a need to restore full muscle efficiency and capacity. The McKenzie method is a method of mechanical diagnosis and therapy of spinal and extremity pain syndromes. It consists of the assessment of symptomatic reactions during a physical examination. With this information, the therapist can note the peripheralisation or centralisation of pain symptoms [21].

The main aim of this study was to assess muscle fatigue during the BST in people with chronic lumbarsacral pain who underwent the McKenzie therapy. The activity of ES, GM and BF was analysed using surface electromyography (EMG) in adult men work- ing in the seated position. Moreover, the asymmetry effect and the relationship between subjective pain assessment and electromyographic parameters of fatigued muscles and also anthropometric parameters were studied.

\section{Materials and methods}

\section{Ethics statement}

The study was approved by the Bioethics Committee of the Poznan University of Medical Sciences. All subjects expressed informed consent in writing to participate in the study. All procedures were conducted according to the Declaration of Helsinki.

\section{Participants}

Project participants included 19 men (mean age: 41.4 years, standard deviation (SD): 6.55 ; mean body mass index (BMI): $27.16 \mathrm{~kg} / \mathrm{m}^{2}$, SD: 3.81) with chronic non-specific lumbar and sacral pain, working in the seated position in front of a computer (mean work experience: 13.53 years, SD: 6.19). The lumbar protocol according to the McKenzie method was used for preliminary classification of subjects [43].

The criterion for inclusion in subsequent tests included the presence of characteristic features of the derangement syndrome. The following exclusion criteria were defined: history of lumbar spine surgery, diagnosed spondylolisthesis, history of hip, knee and ankle joint pain, female sex.

\section{Experimental procedures}

The whole experiment involved three stages of tests. In the first stage, 19 participants were included, among whom a qualified McKenzie therapist determined directional preference and centralization of symptoms. In the second stage $(n=19)$, the participants underwent a Computed Tomography (CT) scan of the lumbar spine. The examination was carried out in an independent diagnostic imaging laboratory. Descriptions of the test results were prepared by a radiologist. All examined subjects were diagnosed with overload degenerative changes in the form of protrusion of intervertebral discs. The exclusion criteria at this stage were: neoplastic disease, previous fractures of the spine. The third stage took place in the Biomechanics Laboratory. The participants were obliged to attend in two independent sessions, during which the fatigue of lumbar and hip joint extensors following the McKenzie therapy was evaluated. The break 
between the sessions was 7 days. Prior to the test, subjects each time took part in a warm-up on a cycle ergometer.

During the first session, a modified BST was performed for the first time with simultaneous measurement of EMG followed by the McKenzie therapy $(n=19)$. After about an hour of rest, a second BST with EMG was performed. During the 7-day break between the sessions, the participants followed an autotherapy schedule. It was recommended to perform the procedure cyclically, every 2 or 3 hours, interrupting work/seating position for a few minutes. Participants had the opportunity to contact a physiotherapist by phone. During the second session the BST with EMG was performed for the third time.

\section{EMG measurement}

The subjects were asked to lie face down on a couch with arms along the body and to expose the test area. Next, the subject's skin was shaved and cleaned. According to SENIAM recommendations, disposable, self-adhesive $\mathrm{Ag} / \mathrm{AgCl}$ electrodes (SORIMEX, Poland, $1 \mathrm{~cm}$ diameter) were placed in a bipolar configuration, parallel to the muscle fibres. The electrodes were placed by a physiotherapist as follows: for ES $-2 \mathrm{~cm}$ on both sides from the spinous processes of the L3 vertebra, for GM - in the middle of the line connecting S2 with the greater trochanter, for $\mathrm{BF}$ - laterally in the middle of the line between the buttock fold and the knee pit [10]. Then the respondents were given detailed instructions on the performance of the BST. During the BST, electromyographic measurements were performed with the use of the 16-channel telemetric EMG TeleMyo 2400T G2 system (Noraxon, USA). The EMG signal was sampled at $1000 \mathrm{~Hz}$ and then filtered (bandwidth: 10-500 Hz). Fatigue of 6 selected lumbar and pelvic muscles was analysed. Three recorded tests were analysed. Signal processing was performed with the MyoResearch XP Master Edition software (Noraxon, USA). Artefacts and noise were visually inspected. The EMG signal was full-wave rectified and smoothed using a root mean square algorithm (RMS) with a 50 millisecond window.

\section{Biering-Sorensen test}

The participants were placed on a couch so that the anterior superior iliac spines were aligned with the edge of the couch (Fig. 1). A modification was applied consisting in the use of fewer stabilising belts (no belt around the ankle joints). Initially, the participants supported their torso with their arms placed on the ground. Both lower limbs were tied to the couch with two belts at pelvis and knee level. The test began by folding the arms across the chest and keeping the torso in a neutral position through isometric contraction of the spinal extensor muscles. The time of maintaining the horizontal position and keeping the head in line with the torso was measured [7]. The beginning of the test was announced by the researcher, the test ended at the discretion of the participant or when the position of the trunk lowered. A standardised verbal incentive was used to help the participants maintain the position as long as possible.

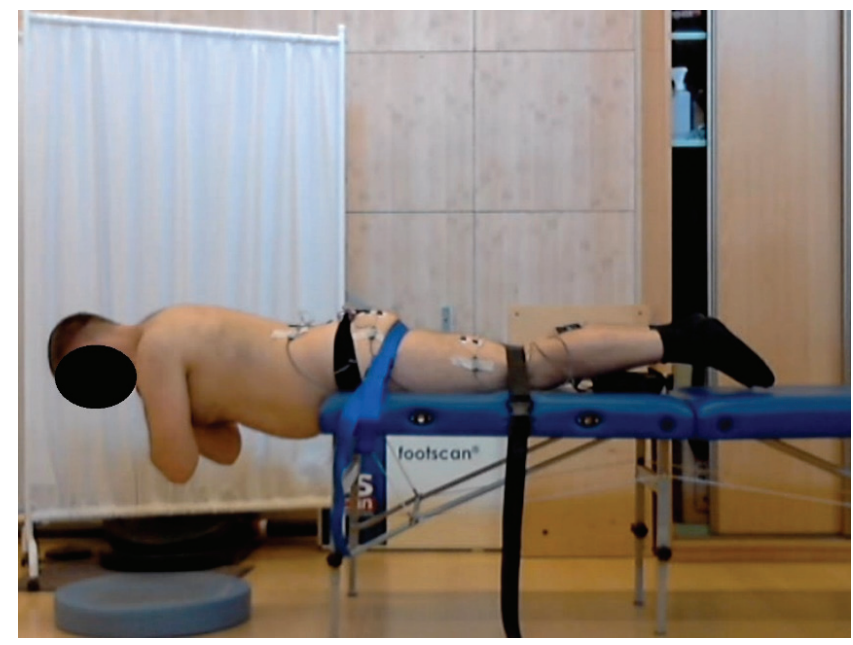

Fig. 1. Illustration of the testing position for the Biering-Sorensen test

\section{McKenzie method therapy}

During the McKenzie therapy, each participant performed an individual torso movement, thanks to which the symptoms were centralised or eliminated. Both static and dynamic procedures were applied according to the principle of difficulty grading. The dynamic hyperextension model was performed in 4 series, 10-15 repetitions each.

\section{VAS scale}

At each stage of the tests, the visual analogue scale (VAS) was used to determine the intensity of back pain [28].

\section{Numerical and statistical methods}

The median frequency (MF) of the EMG signal is a reliable parameter used for the analysis of spinal muscle fatigue [9], [36]. The relationship between MF and time (Fig. 3) is obtained by applying a fast Fourier transform to the time course of the EMG signal. The relationship between MF and time can be approximated by the linear regression model: 


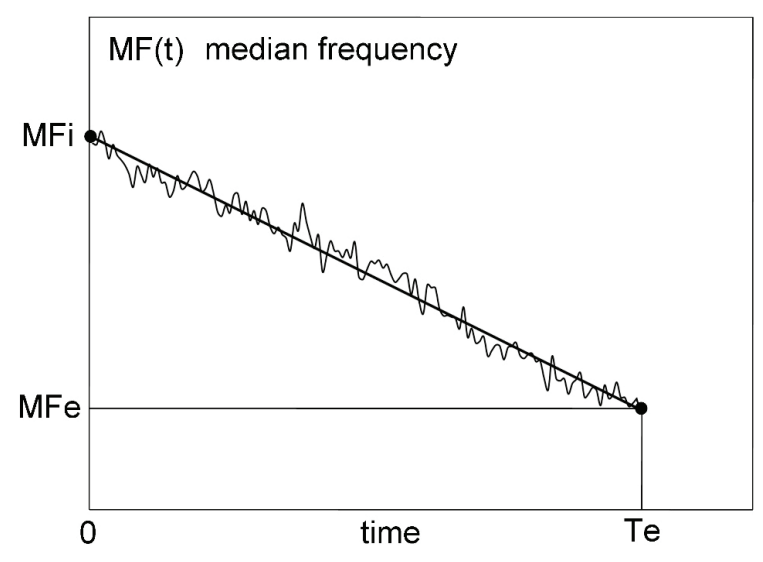

Fig. 2. Relationship between the median frequency and time

$$
\mathrm{MF}(t)=\mathrm{MF}_{\text {slope }} \times t+\mathrm{MFi}
$$

where:

$\mathrm{MF}_{\text {slope }}[\mathrm{Hz} / \mathrm{s}]$ is the slope coefficient of the simple regression,

$\mathrm{MFi}[\mathrm{Hz}]$ is the initial frequency, $\mathrm{MFi}=\mathrm{MF}(0)$,

$\mathrm{MFe}[\mathrm{Hz}]$ is the final frequency, $\mathrm{MFe}=\mathrm{MF}(\mathrm{Te})$,

$\mathrm{Te}[\mathrm{s}]$ is the duration of the BST.

The formula for $\mathrm{MF}_{\text {slope: }}$ :

$$
\mathrm{MF}_{\text {slope }}[\mathrm{Hz} / \mathrm{s}]=(\mathrm{MFe}-\mathrm{MFi}) / \mathrm{Te}
$$

is derived from Eq. (1).

The slope coefficient of the simple regression $\mathrm{MF}_{\text {slope }}$ is normalized to the initial frequency MFi:

$$
\mathrm{NMFs}\left[\mathrm{s}^{-1}\right]=\mathrm{MF}_{\text {slope }} / \mathrm{MFi} \text {. }
$$

The dimensionless quantity dim is also used to describe the time course of the median frequency $\operatorname{MF}(t)$ :

$$
\operatorname{dim}=(M F i-M F e) / M F i .
$$

There is a relationship between dim and NMFs:

$$
\operatorname{dim}=-\mathrm{NMFs} \times \mathrm{Te} .
$$

The NMFs index is useful for the assessment of muscle fatigue, while Te is related to the assessment of their endurance.

Asymmetry of electromyographic parameters of the left and right muscle is assessed according to the following formulas:

$$
\begin{gathered}
\Delta X=\left|X_{R}-X_{L}\right| \\
\Delta X_{N}=\left|X_{R}-X_{L}\right| / \max \left\{\left|X_{R}\right|,\left|X_{L}\right|\right\},
\end{gathered}
$$

where $\Delta X, \Delta X_{N}$ are the absolute and relative asymmetry index, respectively; $X_{R}, X_{L}$ are the parameters for the left and right muscle, respectively.

The parameters $\mathrm{MF}_{\text {slope }}$, MFi (Fourier transform in 1-s windows) and Te were calculated in MyoResearch XP Master software Edition 1.08.38 from Noraxon. The remaining parameters were calculated in Excel.
Statistica (version 13.3) was used for statistical analysis. The Shapiro-Wilk test was used for evaluation of the normality of distribution of variables. Results from the 3 test dates were analysed by ANOVA. Snedecor's F-test and Levene's test were used for the analysis and verification of the equality of variances. The statistical significance of differences between the mean parameters determined on the 3 test dates was tested with Tukey's post hoc test.

\section{Results}

Normal distributions were obtained for 41 out of a total of 56 variables (taking into account all variables from the 3 test dates). Levene's test showed equality of variances of all the analysed variables. In the $F$-test of variance analysis, statistical significance was obtained only for the PA (pain assessment) parameter.

The Te duration of the BST (Table 1) increased on the third date $(112.7 \mathrm{~s})$ compared to the first (98.8 s) and second date $(96.5 \mathrm{~s})$. A similar result was obtained in the case of pain assessment, i.e., a statistically significant decrease of this parameter on the 3 test dates (Table 1). Cohen's effect size coefficient (3.033), particularly concerning the assessment of pain between the first and the third test date, shows a statistically significant result (decrease in PA from 6.22 to 2.89 , Table 1). The effects of increased test duration and simultaneous decrease in pain assessment confirm the effectiveness of the McKenzie therapy.

Table 1. Duration of the BST and pain assessment and the significance of differences between the test dates

\begin{tabular}{|l|c|c|c|c|c|c|}
\hline \multirow{2}{*}{} & \multicolumn{3}{|c|}{ Mean } & \multicolumn{3}{c|}{$p$-value } \\
\cline { 2 - 7 } & I & II & III & I-II & I-III & II-III \\
\hline Te [s] & 98.8 & 96.5 & 112.7 & 0.905 & $0.043^{*}$ & $0.015^{*}$ \\
$n=19$ & 37.6 & 22.4 & 33.2 & 0.074 & 0.392 & 0.572 \\
\hline PA [VAS] & 6.22 & 3.94 & 2.89 & $0.000^{*}$ & $0.000^{*}$ & $0.004^{*}$ \\
$n=18$ & 0.65 & 1.39 & 1.41 & 2.101 & 3.033 & 0.750 \\
\hline
\end{tabular}

${ }^{*} p<0.05$, Tukey's test.

ES Cohen's effect size.

Six parameters were selected for the analysis of EMG signals, i.e., MFi and MFe (Table 2) and NMFs, $\operatorname{dim}, \triangle \mathrm{NMFs}, \triangle \mathrm{dim}$, determined according to formulas (3), (4), (6). The correlation coefficients between the test duration and pain assessment and mean electromyographic parameters (mean values for the left and right muscle) are presented in Table 2. Statisti- 
Table 2. Correlations between electromyographic parameters on the one hand and test duration and pain assessment on the other

\begin{tabular}{|c|c|c|c|c|c|c|}
\hline Parameters & MFi & $\mathrm{MFe}$ & NMFs & $\operatorname{dim}$ & $\Delta \mathrm{NMFs}$ & $\Delta \operatorname{dim}$ \\
\hline \multicolumn{7}{|c|}{ ES } \\
\hline $\mathrm{Te}$ & $\begin{array}{l}0.203^{\mathrm{P}} \\
0.177\end{array}$ & $\begin{array}{c}-0.427^{\mathrm{P}} \\
0.003^{*}\end{array}$ & $\begin{array}{c}0.449 \\
0.000 *\end{array}$ & $\begin{array}{l}0.548^{\mathrm{P}} \\
0.000^{*}\end{array}$ & $\begin{array}{c}-0.069 \\
0.612\end{array}$ & $\begin{array}{l}0.236 \\
0.077\end{array}$ \\
\hline PA & $\begin{array}{c}-0.197 \\
0.153\end{array}$ & $\begin{array}{c}-0.093 \\
0.505\end{array}$ & $\begin{array}{l}0.056 \\
0.687\end{array}$ & $\begin{array}{c}-0.122 \\
0.380\end{array}$ & $\begin{array}{l}0.146 \\
0.293\end{array}$ & $\begin{array}{l}0.128 \\
0.355\end{array}$ \\
\hline \multicolumn{7}{|c|}{ GM } \\
\hline $\mathrm{Te}$ & $\begin{array}{c}-0.023^{\mathrm{P}} \\
0.880\end{array}$ & $\begin{array}{c}-0.228^{\mathrm{P}} \\
0.128\end{array}$ & $\begin{array}{c}0.348 \\
0.012 *\end{array}$ & $\begin{array}{l}0.165 \\
0.248\end{array}$ & $\begin{array}{l}-0.362 \\
0.009 *\end{array}$ & $\begin{array}{c}-0.032 \\
0.823\end{array}$ \\
\hline PA & $\begin{array}{c}-0.181 \\
0.218 \\
\end{array}$ & $\begin{array}{l}0.139 \\
0.347 \\
\end{array}$ & $\begin{array}{c}0.300 \\
0.036^{*}\end{array}$ & $\begin{array}{l}-0.318 \\
0.028^{*}\end{array}$ & $\begin{array}{l}0.057 \\
0.701 \\
\end{array}$ & $\begin{array}{l}0.054 \\
0.716 \\
\end{array}$ \\
\hline \multicolumn{7}{|c|}{ BF } \\
\hline $\mathrm{Te}$ & $\begin{array}{c}0.068^{\mathrm{P}} \\
0.653 \\
\end{array}$ & $\begin{array}{c}0.045^{\mathrm{P}} \\
0.767\end{array}$ & $\begin{array}{c}0.480 \\
0.000^{*}\end{array}$ & $\begin{array}{l}0.152 \\
0.281 \\
\end{array}$ & $\begin{array}{c}-0.048 \\
0.734 \\
\end{array}$ & $\begin{array}{c}0.429 \\
0.002 *\end{array}$ \\
\hline PA & $\begin{array}{c}-0.065 \\
0.657\end{array}$ & $\begin{array}{c}-0.052 \\
0.724\end{array}$ & $\begin{array}{c}-0.116 \\
0.428\end{array}$ & $\begin{array}{l}0.063 \\
0.666\end{array}$ & $\begin{array}{c}-0.114 \\
0.436\end{array}$ & $\begin{array}{c}-0.189 \\
0.193\end{array}$ \\
\hline
\end{tabular}

$* p<0.05$ (Statistical significance is given below correlation coefficients), ${ }^{\mathrm{P}}$ Pearson correlation, $n=46$ (in other cases Spearman's correlation, $n=48-57)$.

cally significant correlation for all 3 muscle pairs (ES, $\mathrm{GM}, \mathrm{BF}$ ) was obtained between the test duration and NMFs slope coefficients. These correlations, all with increasing trends, are presented in Fig. 4. Moreover, it was found that NMFs slope coefficients of the examined muscles correlate with basic anthropometric parameters (in 6 out of 9 cases, Table 3). The decreasing tendency obtained for the correlations presented in Table 3 is indicative of greater fatigue of the examined muscles together with an increase in the subjects mass, body height and BMI, taking the relationships presented in Fig. 4 into account. Therefore, there is a relationship between the three basic anthropometric parameters and the endurance of the tested muscle pairs (measured in Te).

Table 3. Correlations between standardised slope coefficients and anthropometric parameters

\begin{tabular}{|c|c|c|}
\hline $\begin{array}{c}\text { Anthropometric } \\
\text { parameters }\end{array}$ & Muscles & $\begin{array}{c}\text { NMFs } \\
r ; p \text {-values }\end{array}$ \\
\hline & ES & $-0.308 ; 0.020^{*}$ \\
Mass & GM & $-0.164 ; 0.247$ \\
& BF & $-0.424 ; 0.002^{*}$ \\
\hline \multirow{3}{*}{ Height } & ES & $-0.356 ; 0.007^{*}$ \\
& GM & $-0.457 ; 0.001^{*}$ \\
& BF & $-0.161 ; 0.254$ \\
\hline \multirow{3}{*}{ BMI } & ES & $-0.327 ; 0.013^{*}$ \\
& GM & $-0.122 ; 0.391$ \\
& BF & $-0.457 ; 0.001^{*}$ \\
\hline
\end{tabular}

$* p<0.05$.

Spearman correlation, $n=52-57$.

Tukey's tests of six electromyographic parameters (mean values for the left and right muscle) concerning the 3 test dates did not show statistically significant differences, except for the MFe parameter for ES muscles between the second and third test date (Table 4). The values of absolute asymmetry indexes $\triangle \mathrm{NMFs}$ and $\Delta$ dim for the ES, GM, BF muscles on the three test dates and their differences between the test dates (I-II, I-III, II-III) are indicative of a lack of changes in the asymmetry of muscle fatigue following the McKenzie therapy (Table 4).

Asymmetry of electromyographic parameters (left/ right muscle) is expressed by the $\Delta \mathrm{NMFs}$ and $\Delta$ dim asymmetry indexes. Standardization to the $\triangle \mathrm{NMFs}$ and $\Delta$ dim asymmetry indices Eq. (7) does not translate into a statistical improvement in the significance of differences on the 3 test dates. The $p$-value after standardization of $\triangle \mathrm{NMFs}$ and $\Delta \mathrm{dim}$ changes from 0.384 to 0.999 . Given the lack of differentiation of asymmetry indexes (Table 4), the significance of differences in electromyographic parameters was tested separately for the left and right muscle (Table 5). A statistically significant asymmetry effect was obtained only for the ES muscle and the MFi parameter on the 3rd test date, however, the asymmetry does not appear for the MFe parameter on this test date. The asymmetry of the MFi(MFe) parametersis indicative of the difference (left/right) in muscle tension at the beginning (end) of the BST. The absence of statistically significant differences in NMFs (left/right) and dim for the ES, GM, BF muscles on the three test dates confirms the previously provided result on lack of change in muscle fatigue asymmetry (Table 5). The significance of differences between the dates of tests of electromyographic parameters in Table 5 is presented in Table 6 . 
Table 4. Electromyographic parameters and the significance of their differences between the three test dates

\begin{tabular}{|c|c|c|c|c|c|c|c|c|c|c|c|c|}
\hline & \multicolumn{3}{|c|}{$\begin{array}{c}\text { Mean } \\
\text { SD }\end{array}$} & \multicolumn{3}{|c|}{$p$-value } & \multicolumn{3}{|c|}{$\begin{array}{c}\text { Mean } \\
\text { SD }\end{array}$} & \multicolumn{3}{|c|}{$p$-value } \\
\hline & I & II & III & I-II & I-III & II-III & I & II & III & I-II & I-III & II-III \\
\hline & \multicolumn{6}{|c|}{$\mathrm{MFi}[\mathrm{Hz}]$} & \multicolumn{6}{|c|}{$\mathrm{MFe}[\mathrm{Hz}]$} \\
\hline \multirow{2}{*}{ ES } & 75.6 & 76.3 & 73.6 & \multirow[t]{2}{*}{0.911} & \multirow[t]{2}{*}{0.528} & \multirow[t]{2}{*}{0.303} & 42.7 & 45.0 & 39.9 & \multirow[t]{2}{*}{0.474} & \multirow[t]{2}{*}{0.326} & \multirow[t]{2}{*}{$0.033 *$} \\
\hline & 16.5 & 17.2 & 13.1 & & & & 12.5 & 11.2 & 9.2 & & & \\
\hline \multirow{2}{*}{ GM } & 43.0 & 44.0 & 44.0 & \multirow[t]{2}{*}{0.138} & \multirow[t]{2}{*}{0.244} & \multirow[t]{2}{*}{0.944} & 36.7 & 37.3 & 35.9 & \multirow[t]{2}{*}{0.517} & \multirow[t]{2}{*}{0.607} & \multirow[t]{2}{*}{0.114} \\
\hline & 2.7 & 2.9 & 4.3 & & & & 4.6 & 3.8 & 4.6 & & & \\
\hline \multirow{3}{*}{$\mathrm{BF}$} & 83.3 & 86.8 & 87.8 & \multirow[t]{2}{*}{0.230} & \multirow[t]{2}{*}{0.059} & \multirow[t]{2}{*}{0.758} & 68.9 & 73.2 & 72.7 & \multirow[t]{2}{*}{0.318} & \multirow[t]{2}{*}{0.762} & \multirow[t]{2}{*}{0.725} \\
\hline & 12.9 & 16.5 & 14.9 & & & & 14.4 & 15.3 & 15.9 & & & \\
\hline & \multicolumn{6}{|c|}{$10^{4} \times$ NMFs $\left[\mathrm{s}^{-1}\right]^{1}$} & \multicolumn{6}{|c|}{$\operatorname{dim}[\%]^{1}$} \\
\hline \multirow{2}{*}{ ES } & -45.4 & -41.4 & -42.5 & \multirow[t]{2}{*}{0.233} & 0.447 & 0.899 & 41.9 & 39.5 & 44.5 & 0.547 & 0.480 & 0.081 \\
\hline & 16.3 & 10.6 & 16.9 & & & & 15.9 & 13.2 & 13.0 & & & \\
\hline$G M$ & -15.5 & -15.7 & -17.7 & 0.832 & 0.716 & 0.977 & 14.5 & 15.1 & 18.1 & 0.929 & 0.142 & 0.267 \\
\hline GM & 9.4 & 9.8 & 9.9 & & & & 10.1 & 8.3 & 8.2 & & & \\
\hline & -21.6 & -17.4 & -17.4 & 0.480 & 0.679 & 0.943 & 17.5 & 15.6 & 17.3 & 0.921 & 0.531 & 0.320 \\
\hline $\mathrm{BF}$ & 13.0 & 8.9 & 10.8 & & & & 9.4 & 6.0 & 8.1 & & & \\
\hline & & & $10^{4} \times \Delta$ & MFs $\left[\mathrm{s}^{-1}\right.$ & & & & & & {$[\%]^{1}$} & & \\
\hline & 7.0 & 7.0 & 5.2 & 1.000 & 0.564 & 0.563 & 6.5 & 6.7 & 6.0 & 0.998 & 0.959 & 0.939 \\
\hline ES & 6.4 & 5.6 & 4.9 & & & & 6.6 & 6.0 & 5.8 & & & \\
\hline$C M$ & 5.3 & 6.0 & 4.8 & 0.909 & 0.915 & 0.694 & 4.4 & 5.2 & 4.8 & 0.713 & 0.971 & 0.844 \\
\hline GM & 5.3 & 4.5 & 4.9 & & & & 3.1 & 2.7 & 3.9 & & & \\
\hline $\mathrm{BF}$ & 5.0 & 5.6 & 6.8 & 0.732 & 0.516 & 0.933 & 4.1 & 5.4 & 7.6 & 0.476 & 0.084 & 0.555 \\
\hline $\mathrm{BF}$ & 4.0 & 4.0 & 4.0 & & & & 3.4 & 4.1 & 4.5 & & & \\
\hline
\end{tabular}

$* p<0.05$, Tukey's test.

The maximum value of Cohen's effect size is 0.498 .

${ }^{1}$ Multiplication index of $10^{4}$ for NMFs and $\triangle$ NMFs was introduced to unify the format of data in the table, for the same reason, dim and $\Delta$ dim are expressed in $\%$.

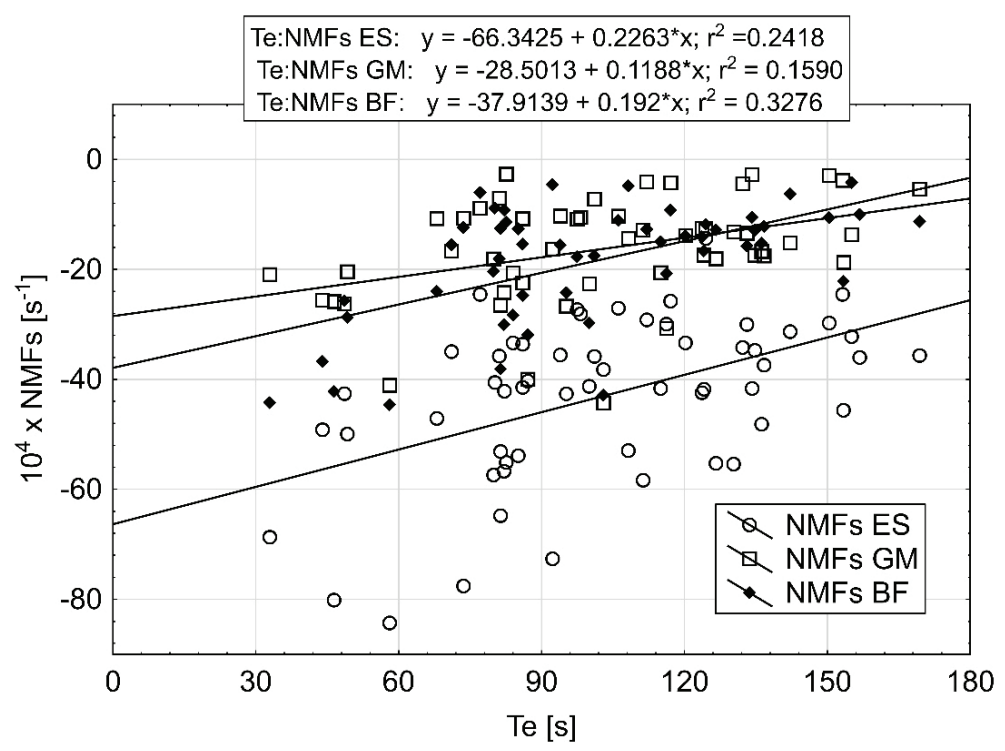

Fig. 3. Illustration of the correlation between NMFs slope coefficients and the duration of the BST

Statistically significant differences between the test dates were obtained only for 3 cases: the MFi parameter (RBF muscle, 1st and 3rd date), and the MFe parameter (LES muscle and LGM, 2nd and 3rd date). To summarize, the results presented in Tables 4-6 are indicative of the fact that electromyographic examinations did not result, with few exceptions, in a statistically significant variability effect on the 3 test dates. 
Table 5. Electromyographic parameters of left and right muscles and the significance of their differences on the three test dates

\begin{tabular}{|c|c|c|c|c|c|c|c|c|c|c|c|c|}
\hline \multirow{3}{*}{ Test date } & \multicolumn{3}{|c|}{$\operatorname{MFi}[\mathrm{Hz}]$} & \multicolumn{3}{|c|}{$\mathrm{MFe}[\mathrm{Hz}]$} & \multicolumn{3}{|c|}{$10^{4} \times \mathrm{NMFs}\left[\mathrm{s}^{-1}\right]$} & \multicolumn{3}{|c|}{$\operatorname{dim}[\%]$} \\
\hline & \multicolumn{2}{|c|}{$\begin{array}{c}\text { Mean } \\
\text { SD }\end{array}$} & \multirow{2}{*}{$p$} & \multicolumn{2}{|c|}{$\begin{array}{l}\text { Mean } \\
\text { SD }\end{array}$} & \multirow{2}{*}{$p$} & \multicolumn{2}{|c|}{$\begin{array}{c}\text { Mean } \\
\text { SD }\end{array}$} & \multirow{2}{*}{$p$} & \multicolumn{2}{|c|}{$\begin{array}{c}\text { Mean } \\
\text { SD }\end{array}$} & \multirow{2}{*}{$p$} \\
\hline & $\mathrm{L}$ & $\mathrm{R}$ & & $\mathrm{L}$ & $\mathrm{R}$ & & $\mathrm{L}$ & $\mathrm{R}$ & & $\mathrm{L}$ & $\mathrm{R}$ & \\
\hline \multicolumn{13}{|c|}{ ES } \\
\hline I & $\begin{array}{l}73.4 \\
16.7\end{array}$ & $\begin{array}{l}77.8 \\
17.1\end{array}$ & 0.095 & $\begin{array}{l}42.8 \\
11.2\end{array}$ & $\begin{array}{l}42.6 \\
14.5\end{array}$ & 1.000 & $\begin{array}{c}-43.6 \\
14.6\end{array}$ & $\begin{array}{c}-47.3 \\
18.9\end{array}$ & 0.367 & $\begin{array}{l}40.4 \\
14.2\end{array}$ & $\begin{array}{l}43.4 \\
18.5\end{array}$ & 0.622 \\
\hline II & $\begin{array}{l}74.1 \\
17.4\end{array}$ & $\begin{array}{l}78.6 \\
17.8\end{array}$ & 0.076 & $\begin{array}{l}44.5 \\
10.1\end{array}$ & $\begin{array}{l}45.5 \\
12.8\end{array}$ & 0.974 & $\begin{array}{c}-40.0 \\
11.6\end{array}$ & $\begin{array}{c}-42.8 \\
11.3\end{array}$ & 0.676 & $\begin{array}{l}38.2 \\
13.7\end{array}$ & $\begin{array}{l}40.9 \\
14.1\end{array}$ & 0.722 \\
\hline III & $\begin{array}{l}71.1 \\
14.2 \\
\end{array}$ & $\begin{array}{l}76.2 \\
12.8 \\
\end{array}$ & $0.030^{*}$ & $\begin{array}{c}39.3 \\
9.3 \\
\end{array}$ & $\begin{array}{c}40.5 \\
9.8\end{array}$ & 0.958 & $\begin{array}{c}-41.4 \\
18.6 \\
\end{array}$ & $\begin{array}{c}-43.5 \\
15.8 \\
\end{array}$ & 0.869 & $\begin{array}{l}43.1 \\
14.3 \\
\end{array}$ & $\begin{array}{l}45.9 \\
12.8 \\
\end{array}$ & 0.703 \\
\hline \multicolumn{13}{|c|}{ GM } \\
\hline I & $\begin{array}{c}43.1 \\
3.1\end{array}$ & $\begin{array}{c}42.5 \\
3.5\end{array}$ & 0.999 & $\begin{array}{c}37.0 \\
5.0 \\
\end{array}$ & $\begin{array}{c}36.2 \\
4.2 \\
\end{array}$ & 0.793 & $\begin{array}{c}-14.6 \\
10.2\end{array}$ & $\begin{array}{c}-15.6 \\
10.3\end{array}$ & 0.886 & $\begin{array}{l}14.0 \\
11.1 \\
\end{array}$ & $\begin{array}{l}14.3 \\
10.1\end{array}$ & 0.973 \\
\hline II & $\begin{array}{c}44.2 \\
3.0 \\
\end{array}$ & $\begin{array}{c}43.5 \\
3.6 \\
\end{array}$ & 0.982 & $\begin{array}{c}38.3 \\
4.2 \\
\end{array}$ & $\begin{array}{c}36.3 \\
3.6 \\
\end{array}$ & 0.102 & $\begin{array}{c}-14.6 \\
8.7 \\
\end{array}$ & $\begin{array}{c}-17.9 \\
11.1 \\
\end{array}$ & 0.607 & $\begin{array}{c}13.5 \\
8.0 \\
\end{array}$ & $\begin{array}{c}16.1 \\
9.2 \\
\end{array}$ & 0.641 \\
\hline III & $\begin{array}{c}44.1 \\
4.5 \\
\end{array}$ & $\begin{array}{c}43.3 \\
4.8 \\
\end{array}$ & 0.998 & $\begin{array}{c}36.5 \\
5.2 \\
\end{array}$ & $\begin{array}{c}36.1 \\
4.8 \\
\end{array}$ & 1.000 & $\begin{array}{c}-16.8 \\
10.3 \\
\end{array}$ & $\begin{array}{c}-16.2 \\
11.3 \\
\end{array}$ & 1.000 & $\begin{array}{c}17.2 \\
9.7 \\
\end{array}$ & $\begin{array}{c}16.4 \\
9.0 \\
\end{array}$ & 1.000 \\
\hline \multicolumn{13}{|c|}{$\mathrm{BF}$} \\
\hline I & \begin{tabular}{|l|}
83.4 \\
13.4 \\
\end{tabular} & $\begin{array}{l}82.2 \\
14.4 \\
\end{array}$ & 0.963 & $\begin{array}{l}69.8 \\
14.4 \\
\end{array}$ & $\begin{array}{l}67.9 \\
14.9 \\
\end{array}$ & 0.943 & $\begin{array}{c}-19.8 \\
12.8 \\
\end{array}$ & $\begin{array}{c}-21.8 \\
14.1 \\
\end{array}$ & 1.000 & $\begin{array}{c}16.4 \\
9.8 \\
\end{array}$ & $\begin{array}{c}17.6 \\
9.7 \\
\end{array}$ & 1.000 \\
\hline II & $\begin{array}{l}87.6 \\
15.6\end{array}$ & $\begin{array}{l}86.0 \\
18.8 \\
\end{array}$ & 0.987 & $\begin{array}{l}73.9 \\
14.7 \\
\end{array}$ & $\begin{array}{l}72.4 \\
16.6 \\
\end{array}$ & 0.972 & $\begin{array}{c}-17.2 \\
10.4 \\
\end{array}$ & $\begin{array}{c}-17.6 \\
8.5\end{array}$ & 1.000 & $\begin{array}{c}15.5 \\
8.3\end{array}$ & $\begin{array}{c}15.8 \\
5.3\end{array}$ & 1.000 \\
\hline III & $\begin{array}{l}88.2 \\
15.4 \\
\end{array}$ & $\begin{array}{l}88.5 \\
17.6 \\
\end{array}$ & 0.994 & $\begin{array}{l}73.7 \\
16.7 \\
\end{array}$ & $\begin{array}{l}73.3 \\
18.0 \\
\end{array}$ & 0.990 & $\begin{array}{c}-16.8 \\
10.2\end{array}$ & $\begin{array}{c}-17.2 \\
12.9\end{array}$ & 1.000 & $\begin{array}{c}16.8 \\
7.8 \\
\end{array}$ & $\begin{array}{l}17.2 \\
10.8 \\
\end{array}$ & 1.000 \\
\hline
\end{tabular}

$* p<0.05$, Tukey's test.

The maximum value of Cohen's effect size is 0.377 .

Table 6. Significance of differences in electromyographic parameters from Table 5 between the test dates

\begin{tabular}{|c|c|c|c|c|c|c|c|c|c|c|c|c|}
\hline & \multicolumn{3}{|c|}{ MFi } & \multicolumn{3}{c|}{ MFe } & \multicolumn{3}{c|}{ NMFs } & \multicolumn{3}{c|}{$\operatorname{dim}$} \\
\cline { 2 - 50 } & I-II & I-III & II-III & I-II & I-III & II-III & I-II & I-III & II-III & I-II & I-III & II-III \\
\hline LES & 0.953 & 0.551 & 0.379 & 0.608 & 0.117 & $0.013^{*}$ & 0.339 & 0.667 & 0.841 & 0.628 & 0.490 & 0.109 \\
\hline RES & 0.888 & 0.648 & 0.372 & 0.448 & 0.652 & 0.102 & 0.272 & 0.397 & 0.965 & 0.624 & 0.631 & 0.167 \\
\hline LGM & 0.155 & 0.371 & 0.854 & 0.178 & 0.603 & $0.023^{*}$ & 0.999 & 0.619 & 0.651 & 0.977 & 0.175 & 0.119 \\
\hline RGM & 0.262 & 0.361 & 0.976 & 0.952 & 0.999 & 0.937 & 0.616 & 0.997 & 0.662 & 0.702 & 0.559 & 0.971 \\
\hline LBF & 0.388 & 0.595 & 0.934 & 0.460 & 0.997 & 0.505 & 0.688 & 0.788 & 0.984 & 0.996 & 0.617 & 0.565 \\
\hline RBF & 0.276 & $0.003^{*}$ & 0.108 & 0.495 & 0.500 & 1.000 & 0.555 & 0.722 & 0.960 & 0.951 & 0.526 & 0.357 \\
\hline
\end{tabular}

$p<0.05$, Tukey's test.

The maximum value of Cohen's effect size is 0.536 .

\section{Discussion}

The aim of this study was to assess the effectiveness of the McKenzie method in subjects with back pain by conducting an electromyographic analysis of selected muscles subjected to the BST on three test dates. No short-term evaluation of the above mentioned physiotherapeutic method using electromyographic analysis of a specific group of subjects with LBP has been performed so far. The most important results of these tests confirm the beneficial effect of the McKenzie method on pain levels and muscle endurance in the selected group of subjects. The duration of isometric tension of the tested muscles during the BST was prolonged in the absence of increase in their fatigue level and the pain level decreased on subsequent test dates. Comparison of the McKenzie method with other physiotherapeutic techniques is a common practice used to confirm or evaluate its effectiveness [4], [5], [20]. According to Namnaqani et al. [27], the presented evidence confirms the effec- 
tiveness of the McKenzie therapy compared to manual therapy in reducing pain and disability levels in subjects with chronic back pain. Schenk, Jozefczyk and Kopf [35] and Ahmed et al. [2] also noted a reduction in lumbar pain following the McKenzie therapy. It should be noted that in all the analysed articles, subjective assessment was based on, among others, VAS, Roland Morris Disability Questionnaire or Oswestry Disability Index. The modified Schober's test was used for objective assessment of the flexion and extension range of motion of the lumbar spine [4]. The advantage of this paper is the analysis of objective and subjective results of tests proposed immediately before and after the application of the McKenzie method. The objective results include physical measurement (duration of the test) and EMG, while pain levels were assessed subjectively. The analysis of BST duration and pain levels confirm the beneficial effect of the McKenzie method in the selected group of subjects. The main findings of Biering-Sorensen [7] after a one-year observation of subjects were that high isometric endurance of back muscles can prevent the first occurrence of LBP. Thanks to the application of the McKenzie method in this study, an improvement in muscle endurance was observed, which has practical application in the rehabilitation of LBP.

Taking the anthropometric parameters in the studied group of men into account, a statistically significant increase in muscle fatigue was observed along with an increase in body mass, body height and BMI. Earlier studies also showed significant correlations between body mass and endurance in the BST [19], [32]. According to Kankaanapaa et al. [18], in heavier people, especially women and younger people, spinal muscle fatigue occurs earlier. All the more so, the problem will occur in men in whom an increase in body mass is particularly manifested by the occurrence of abdominal obesity [15]. As a result, the torque of the torso, which overloads the L1-S1 section, is going to increase by extending the lever arm of the gravity. Thus, the muscular system, whose function is to stabilise the lumbar spine, is additionally loaded, which, in consequence, over time, causes greater chronic overloads [1], [34]. Therefore, in this study, a group of men with a higher body mass and height had weaker muscles stabilising the lumbar spine already at the beginning of the study, i.e., a higher muscle fatigue during the BST was to be expected. A significant correlation between body mass and BST results was also observed in male fire fighters [32]. Therefore, in addition to the previously mentioned increase in muscle endurance, a reduction in body mass will also have an impact on preventing LBP in the future.
There were also publications analysing the influence of psychological factors on the results of the BST [27]. This study did not analyse these factors. According to Mannion et al. [24], higher levels of mental disorders or negative beliefs are significant predictors of poor endurance test results.

Authors of other publications assess muscle endurance using the BST by comparing healthy individuals with LBP symptoms before and after rehabilitation. The BST was used in the Nassif et al. [28] study to assess strength and endurance training. The physical activity proposed to automotive industry workers confirmed numerous health benefits, especially in the group of people with chronic LBP. Sung [37] studied the impact of core stabilization and spinal flexibility exercise on, among other things, back muscle endurance in people with chronic LBP. Changes in muscle fatigue following a 4-week therapy were not satisfactory.

Electromyographic tests in this study did not show any changes in asymmetry indices concerning fatigue of the examined muscles on the three test dates, except for the asymmetric ES muscle pair tension at the beginning of the BST on the third test date, but it iwas not directly related to the effect of muscle fatigue, as the MFi parameter (also MFe) did not correlate with the duration of the BST. The effect of fatigue asymmetry in the LBP group appeared also in studies by Srinivasan and Balasubramanian [36] after a short training session on a bicycle. The aim of the study was to show the consequences of short-term physical activity in people with LBP, i.e., a higher and uneven level of muscle corset fatigue compared to a healthy group. The author emphasizes that the possibility of deterioration of the subjects' condition should be taken into account when using bicycle as a rehabilitation tool [39]. In many publications [17], [29], [35], the concept of asymmetry is related to the occurrence of LBP in subjects. There is a significant relationship between neuromuscular imbalance of the ES and the occurrence of LBP [35]. According to Hides et al. [16], asymmetry may indicate that subjects suffer from unilateral pain. Nadler et al. [26] studied the relationship between LBP episodes and hip muscle asymmetry in academic athletes. The results showed that hip joint extensors in female athletes with LBP had a 9.6\% significantly higher asymmetry compared to women without pain symptoms. Hence the conclusion that high levels of asymmetry are associated with posture problems and LBP, and screening may be an important tool in their prevention [29]. Given the fact that muscular imbalance may predispose the onset of back pain, RoseDulcina et al. [33] also focused on the asymmetry 
aspect of the LBP group. It turned out that the analysed lumbar muscles did not show patterns of asymmetric fatigue, as it was the case in most published papers [36].

\section{Conclusions}

The McKenzie method of diagnosis and therapy is an effective tool in reducing the level of lumbar pain and improving ES, GM and BF muscle endurance. The increase in the endurance of back muscles and correct body mass contribute to the reduction of LBP episodes. Electromyographic tests did not show statistically significant changes in ES, GM and BF muscle fatigue asymmetry indexes during the BST at any stage of the McKenzie therapy.

\section{References}

[1] Adams M., Bogduk N., Burton K., Dolan P., The Biomechanics of Back Pain, ${ }^{\text {rd }}$ Edition, 2012. Churchill Levingstone.

[2] AhMEd G.M., Ramzy G.M., Rezk M.Y., ABdelaZiz N.G.M.M., The Effect of McKenzie Assessment and Treatment Method on Patients with Chronic Low Back Pain with Radiculopathy, Single Blinded Randomized Controlled Trial, IJHS, 2019, 7 (1), 7-17.

[3] Airaksinen O., Brox J.I., Cedraschi C., Hildebrandt J., Klaber-Moffett J., Kovacs F. et al., Chapter 4, European guidelines for the management of chronic nonspecific low back pain, Eur. Spine J., 2006, 15 (2), 192-300.

[4] Anggiat L., Hon W.H.C., BaAit S.N., Mawaddah N., Comparison Between Proprioceptive Neuromuscular Facilitation and Mckenzie Method in Lumbar Range of Motion on NonSpecific Low Back Pain, PSHR, 2020, 9 (1), 63-71.

[5] Anggiat L., Hon W.H.C., Sokran S., Mohammad N., The changes of functional disability in non-specific low back pain among university population after proprioceptive neuromuscular facilitation and Mckenzie method, IJMAES, 2020, 6 (1), 656-667.

[6] Applegate M.E., France C., Russ D., LeitKam S.T., Thomas J., Determining Physiological and Psychological Predictors of Time to Task Failure on a Virtual Reality Sørensen Test in Participants With and Without Recurrent Low Back Pain: Exploratory Study, JMIR Serious Games, 2018, 6 (3), e10522, DOI: 10.2196/10522.

[7] BIERING-SORENSEn F., Physical measurements as risk indicators for low-back trouble over a one-year period, Spine, 1984, 9 (2), 106-119.

[8] Coorevits P., Danneels L., CAmbier D., Ramon H., VANDERSTRAeten G., Assessment of the validity of the Biering-Sørensen test for measuring back muscle fatigue based on EMG median frequency characteristics of back and hip muscles, J. Electromyogr. Kinesiol., 2008, 18 (6), 997-1005.

[9] Cram J., Kasman G., Holtz J., Introduction to surface EMG, Maryland: Aspen Publishing, Gathersburg, PA, 1998, 336-70, 1.
[10] Davarian S., Maroufi N., Ebrahimi I., Farahmand F., PARNIANPOUR M., Trunk muscles strength and endurance in chronic low back pain patients with and without clinical instability, J. Back Musculoskelet. Rehabil., 2012, 25 (2), 123-129.

[11] Dedering Å., Németh G., Harms-Ringdahl K., Correlation between electromyographic spectral changes and subjective assessment of lumbar muscle fatigue in subjects without pain from the lower back, Clin. Biomech., 1999, 14 (2), $103-111$.

[12] Demoulin C., Vanderthommen M., Duysens C., Crielaard J.M., Spinal muscle evaluation using the Sorensen test: a critical appraisal of the literature, Joint Bone Spine, 2006, 73 (1), 43-50.

[13] Ferrari S., Manni T., Bonetti F., Villafañe J.H., Vanti C., A literature review of clinical tests for lumbar instability in low back pain: validity and applicability in clinical practice, Chiropr. Man Therap., 2015, 23, 14.

[14] Frilander H., Solovieva S., Mutanen P., Pihlajamaki H., HELIOVAARA M., VIIKARI-JUNTURA E., Role of overweight and obesity in low back disorders among men: a longitudinal study with a life course approach, BMJ Open, 2015, 5, e007805.

[15] Hallegraeff J.M., Krijnen W.P., Van Der Schans C.P., DE GREEF M.H.G., Expectations about recovery from acute non-specific low back pain predict absence from usual work due to chronic low back pain: a systematic review, J. Physiother., 2012, 58 (3), 165-172.

[16] Hides J., Gilmore C., Stanton W., Bohlscheid E., Multifidus size and symmetry among chronic LBP and healthy asymptomatic subjects, Man Ther., 2008, 13 (1), 43-49.

[17] JABŁoŃSKA M., Fryzowicz A., OGURKowsKa M., Electromyographic evaluation of selected muscles during active hip extension in men treated McKenzie method, Acta Bioeng. Biomech., 2020, 22 (3), 23-31.

[18] KanKaAnPäÄ M., LAAKSONEN D., TAimela S., KoKKo S.M., AiraKsinen O., Hanninen O., Age, sex, and body mass index as determinants of back and hip extensor fatigue in the isometric Sorensen back endurance test, Arch. Phys. Med. Rehabil., 1998, 79 (9), 1069-1075.

[19] Kauser M., SidiQ M., Mathur H., Maruthy P., QAsim M., Effectiveness of Home Based ExcerciseProgrammes for Patients Suffering from Low Back Pain: A Systematic Review, IJCRT, 2020, 8 (3).

[20] Lam O.T., Strenger D.M., Chan-Fee M., Pham P.T., Preuss R.A., RobBInS S.M., Effectiveness of the Mckenzie method of mechanical diagnosis and therapy for treating low back pain: Literature review with meta-analysis, J. Orthop. Sports Phys. Ther., 2018, 48 (6), 476-490.

[21] Latimer J., Maher C.G., Refshauge K., Colaco I., The reliability and validity of the Biering-Sorensen test in asymptomatic subjects and subjects reporting current or previous nonspecific low back pain, Spine, 1999, 24 (20), 2085-2089.

[22] Lu W.W., Luk K.D., Cheung K.M., Wong Y.W., LeOng J.C., Back muscle contraction patterns of patients with low back pain before and after rehabilitation treatment: an electromyographic evaluation, J. Spinal Disord., 2001, 14 (4), 277-282.

[23] Mahato N., Muscle Function In Low Back Pain: Is Bigger And Stronger What Matters?, J. Bangladesh Soc. Physiol., 2017, 12 (1), 41-51.

[24] Mannion A.F., O'Riordan D., DvoraK J., Masharawi Y., The relationship between psychological factors and performance on the Biering-Sørensen back muscle endurance test, Spine J., 2011, 11 (9), 849-857. 
[25] McCormack H.M., Horne D.J., Sheather S., Clinical applications of visual analogue scales: a critical review, Psychol. Med., 1988, (18), 1007-1019.

[26] Nadler S.F., Malanga G.A., Deprince M., Stitik T.P., FEINBERG J.H., The relationship between lower extremity injury, low back pain, and hip muscle strength in male and female collegiate athletes, Clin. J. Sport Med., 2000, 10 (2), 89-97.

[27] NAMNAQANI F.I., MASHABI A.S., YASEEN K.M., AlSHEHRI M.A., The effectiveness of McKenzie method compared to manual therapy for treating chronic low back pain: a systematic review, J. Musculoskelet Neuronal Interact., 2019, 19 (4), 492-499.

[28] Nassif H., Brosset N., Guillaume M., Delore-Milles E., TAFflet M., Buchholz F., Toussaint J.F., Evaluation of a randomized controlled trial in the management of chronic lower back pain in a French automotive industry: an observational study, Arch. Phys. Med. Rehabil., 2011, 92 (12), 1927-1936.

[29] Nuzzo J.L., MAYer J.M., Body Mass Normalization for Isometric Tests of Muscle Endurance, J. Strength Cond. Res., 2013, 27 (7), 2039-2045.

[30] O’Sullivan P.B., Mitchell T., Bulich P., Waller R., HoLte J., The relationship beween posture and back muscle endurance in industrial workers with flexion-related low back pain, Man Ther., 2006, 11 (4), 264-271.

[31] Ogurkowska M., Kawalek K., Pathological changes in the lumbar intervertebral discs among professional field hockey players, J. Sport Med. Phys. Fit., 2016, 56 (1-2), 85-91.

[32] Renkawitz T., Boluki D., GRIFKA J., The association of low back pain, neuromuscular imbalance, and trunk extension strength in athletes, Spine J., 2006, 6 (6), 673-683.
[33] Rose-Dulcina K., Armand S., Dominguez D.E., Genevay S., Vuillerme N., Asymmetry of lumbar muscles fatigability with non-specific chronic low back pain patients, Eur. Spine J., 2019, 28 (11).

[34] Roy S.H., De LuCa C.J., EmLey M., Buiss R.J., Spectral electromyographic assessment of back muscles in patients with low back pain undergoing rehabilitation, Spine, 1995, 20 (1), 38-48.

[35] Schenk R.J., Jozefczyk C., Kopf A., A Randomized Trial Comparing Interventions in Patients with Lumbar Posterior Derangement, J. Man Manip. Ther., 2003, 11 (2), 95-102.

[36] SRINIVASAN J., BALASUbRAmanian V., Low back pain and muscle fatigue due to road cycling - An sEMG study, J. Body Mov. Ther., 2007, 11 (3), 260-266.

[37] Sung P.S., Disability and back muscle fatigability changes following two therapeutic exercise interventions in participants with recurrent low back pain, Med. Sci. Monit., 2013, 19, 40-48.

[38] Tikkanen O., Hahkana P., Pesola A.J., Häkkinen K., Rantalainen T., Havu M., Pullinen T., Finni T., Muscle Activity and Inactivity Periods during Normal Daily Life, PLoS One, 2013, 8 (1), e52228.

[39] Wang-Price S., Almadan M., Stoddard C., Moore D., Recovery of Hip and Back Muscle Fatigue Following a Back Extension Endurance Test, Int. J. Exerc. Sci., 2017, 10 (2), 213-224.

[40] ZygmańsKa M., BŁAsZcZyK A., Wegner K., SAMBORSKI W., OGuRKowska M., Assessment of overload changes in the lumbar spine of employees with sedentary nature of work, Fizjoterapia Polska, 2018, 18 (1), 62-73. 